\title{
The Role of the Pharmacist in the Treatment of Patients with Infantile Hemangioma Using Propranolol
}

\author{
Saul Castaneda (D) - Samuel Melendez-Lopez · Esbeydy Garcia •
}

Hermelinda De la Cruz · Jose Sanchez-Palacio

Received: June 22, 2016 / Published online: July 26, 2016

(C) The Author(s) 2016. This article is published with open access at Springerlink.com

\begin{abstract}
Introduction: Infantile hemangiomas $(\mathrm{IH})$ are the most common benign vascular tumors of childhood, with an incidence of 5-10\% during the first year of age. Propranolol is considered the first-line treatment for this condition. Potentially there is a high probability of negative results to therapy, because in many countries there are no treatment protocols or propranolol formulations appropriate for the pediatric population. The objective of the present study was to evaluate the impact of pharmacist interventions such as detecting, analyzing, and solving problems presented
\end{abstract}

Enhanced content To view enhanced content for this article go to http://www.medengine.com/Redeem/ D3E4F06050C2BEC3.

\section{S. Castaneda $(\bowtie)$}

Department of Pharmacy, Children's Hospital of the Californias, Tijuana, Baja California, Mexico

e-mail: saulcashe@gmail.com

S. Melendez-Lopez · H. De la Cruz ·

J. Sanchez-Palacio

Faculty of Chemical Sciences and Engineering,

Autonomous University of Baja California, Tijuana,

Mexico

E. Garcia

Department of Pediatric Dermatology, Children's

Hospital of the Californias, Tijuana, Mexico during treatment with propranolol in patients with IH.

Methods: An open observational prospective study was performed over 25 months in a group of pediatric patients diagnosed with infantile hemangioma treated with propranolol. Pharmacist participation consisted of development of an extemporaneous formulation and counseling the child's parents. At each visit to the pharmacy service, family members were interviewed, detecting and classifying problems related to treatment.

Results: Sixty-three children with IH were treated during the period under review. Patient ages ranged from 3 to 11 months old; $64 \%$ were female and $36 \%$ were male. Forty-nine problems in 30 patients were detected, principally inadequate dose (18.4\%), non-adherence to treatment $(16.3 \%)$, side effects (14.3\%), and wrong administration (14.3\%). Of the problems detected, $81.6 \%$ were resolved. Interventions by the pharmacist in 27 patients were intensive counseling on adherence to therapy (20\%), detection of adverse effects $(11.4 \%)$, and adjustment of the dose $(22.9 \%)$. In $95.2 \%$ of patients a good 
response to treatment was obtained compared with $77.2 \%$ reported in European studies without pharmacist intervention.

Conclusion: It seems that pharmacist participation increases adherence to treatment and reduces the likelihood of adverse effects, allowing for safe and effective therapy in patients with $\mathrm{IH}$.

Keywords: Dermatology; Drug safety; Infantile hemangioma; Pediatric; Pharmaceutical intervention; Pharmacist; Propranolol

\section{INTRODUCTION}

Infantile hemangiomas (IH) are the most common benign vascular tumors of childhood, with a prevalence of $5-10 \%$ during the first year of age. The condition is more frequent in Caucasians and premature infants, and three times more frequent in females than in males [1]. IH can affect any area of the body's surface, although in most cases they tend to be located in the head and neck area. Treatments include the use of drugs such as corticosteroids, $\beta$-blockers, immunosuppressants, and surgery or laser pulse [2].

In 2014 the US Food and Drug Administration (FDA) approved the use of propranolol to treat this condition, introducing a new therapeutic strategy for these patients. Propranolol is a nonselective adrenergic $\beta$-blocker used for more than 50 years in the treatment of hypertension and heart failure in children. The effect in reducing IH was discovered by Léauté-Labrèze in 2008 [3]. The proposed mechanism of action is a decrease in growth factors that produce angiogenesis and possible acceleration of apoptosis of undifferentiated vascular cells [4].
Various clinical studies published around the world demonstrate the efficacy and safety of propranolol in patients with IH $[5,6]$, yet in Mexico and other countries there are no studies that indicate the best treatment, such as proper dosage, age of treatment initiation, duration, and side effects. So in some cases treatment is ineffective or unsafe [6, 7]. Another limitation is the lack of a commercial formulation of propranolol for pediatric patients in Latin American countries, making the outpatient therapy and adherence to treatment difficult as well as expensive if a foreign product is used. Because of limitations in the treatment of patients with IH, outpatient therapy is difficult, causing medication errors or even death in some cases [8].

Currently there are no reports on the role of the pharmacist in the therapy of patients with $\mathrm{IH}$, which makes pharmacists a group of special interest; family education is essential, as active and observant parents and family members are of utmost importance to ensure success and prevent complications in therapy [8]. The aim of this study was to evaluate the effect of pharmacist's interventions on detecting, analyzing, and solving problems related to the use of propranolol in pediatric patients diagnosed with IH to optimize therapy.

\section{METHODS}

\section{Study Design}

An open observational prospective study was performed. Pediatric patients diagnosed with IH who came to the outpatient pharmacy at the Children's Hospital of the Californias during the period from December 2013 to April 2016 participated in the study. Propranolol syrup was 
dispensed every 15 days during the treatment period.

\section{Population Studied}

The population consisted of patients with ages ranging from 2 to 18 months of age, with the diagnosis of IH treated exclusively with propranolol. In almost all cases, children were the first or second child in the family, with parents aged 20-30 years old, and low-middle level socioeconomic and educational level. The criteria for initiating therapy were based on medical indications, such as functional impairment, ulceration, and aesthetic complications. Before starting treatment the physician performed a medical history, taking vital signs, and physical examinations to confirm that the patients did not have any contraindications to propranolol.

\section{Follow-up by Dáder Method}

In this study we used the Dáder method of pharmacotherapeutic follow-up, in which interviews were carried out between the family of the patient and the clinical pharmacist [9]. A monthly schedule of appointments with the physician and an interview with the pharmacist was designed. During the first 3 months, interviews were conducted using questionnaires with open-ended questions about the problems and concerns about the health of the patient and on the use of propranolol. Follow-up appointments were scheduled with the purpose of solving possible problems related to the use of propranolol.

\section{Preparation of Medication}

The pharmacist was responsible for the preparation of the syrup of propranolol at concentrations of 1 and $2 \mathrm{mg} / \mathrm{mL}$. The syrup was prepared using propranolol $\mathrm{HCl}$ tablets $\left(\right.$ Inderalici ${ }^{\circledR}$ ) and United States Pharmacopeia (USP) grade sucrose in accordance with the standard procedures of the operation described in the Mexican Pharmacopoeia and the relevant literature [10]. Flavors were added to facilitate administration of the medication. The preparation of the propranolol formulation was individualized according to the dosage prescribed by the physician, with an expiration date of 15 days. The family returned to the pharmacy every 15 days to obtain a new supply of the syrup until the end of treatment.

\section{Pharmacist Intervention}

The clinical pharmacist was responsible for developing and designing an intervention plan, which was based primarily on educating the parents and relatives of patients in order to increase adherence to treatment. One-to-one interviews were performed with relatives regarding the current condition of the child, available treatments and therapy with propranolol, as well as the correct way to administer and store the syrup. In a second appointment, a printed information sheet was given and parents' questions related to the treatment were answered. Printouts for each patient were used to describe the most relevant information on the medication provided (adverse reactions, the correct administration, drug interactions, storage, etc.).

\section{Duration of Follow-up}

The duration of treatment in Mexican patients with HI had not been established, so the monitoring of each child was dependent on the duration of the therapy up to a maximum of nine appointments. Six months after the 
completion of treatment, patients' family members were contacted via telephone to detect any regrowth or possible adverse reaction.

\section{Clinical Efficacy of Propranolol in Treating $\mathrm{IH}$}

Evaluation of treatment, based on clinical examination and photographs, was conducted by the team of dermatologists, surgeons, pediatricians, and the pharmacist. The efficacy of propranolol was evaluated according to a clinical visual scale and measurements of $\mathrm{IH}$. Therapy was considered to provide an excellent or good response with a greater than 60\% reduction in size [11].

\section{Statistical Analysis}

Analysis was performed using the Sigma plot 13.0 software for Windows. All data are expressed as numbers and percentages, or means and standard deviation.

\section{Compliance with Ethics Guidelines}

All procedures followed were in accordance with the ethical standards of the responsible committee on human experimentation (institutional and national) and with the Helsinki Declaration of 1964, as revised in 2013. Informed consent was obtained from all patients for being included in the study.

The study was approved by the ethics committee of the Children's Hospital of the Californias, and the parents of the patients signed an informed consent after agreeing to participate.

\section{RESULTS}

A total of 63 patients with $\mathrm{IH}$, with ages ranging from 3 to 11 months of age (64\% female, 36\% male) were evaluated during the follow-up period by the pharmacist, with an average of $8.7 \pm 1.4$ appointments. Table 1 summarizes the demographic data of patients with $\mathrm{IH}$.

\section{Problems Related to the Use of Propranolol}

Forty-nine problems related to the use of propranolol were detected in 30 patients, corresponding to $47.6 \%$ of all of patients. Of the problems detected, $40 \quad(81.6 \%)$ were resolved. The principal problems identified were unsuitable dose (18.4\%) and non-adherence to treatment (16.3\%). One case of discontinuation of therapy occurred during the study (2\%). The problems related to the use of propranolol are shown in Table 2.

\section{Pharmacist Interventions}

The role of the pharmacist in therapy consisted of continuous monitoring and interventions in cases where there were problems with drug treatment. These interventions consisted in promoting adherence to treatment (20\%), modifying dosing intervals (14.3\%), and dosage adjustment (22.9\%). In 92\% of interventions, the pharmacist's recommendation was accepted and approved by the attending physician. Table 1 notes the interventions made.

During the 25-month study, 504 pharmaceutical appointments were made and 1421 extemporaneous formulations of 
Table 1 Problems detected and pharmacist's interventions during treatment using propranolol in patients with infantile hemangioma

\begin{tabular}{|c|c|c|}
\hline & $n$ & Percentage \\
\hline \multicolumn{3}{|c|}{ Problems related to the use of propranolol } \\
\hline Inadequate dose prescribed & 9 & 18.4 \\
\hline Non adherence & 8 & 16.3 \\
\hline Incorrect dose administered & 7 & 14.3 \\
\hline Adverse effects & 7 & 14.3 \\
\hline Dose omission & 6 & 12.2 \\
\hline Wrong frequency of administration & 5 & 10.2 \\
\hline $\begin{array}{l}\text { Wrong medication labeling in } \\
\text { preparation }\end{array}$ & 2 & 4.1 \\
\hline Drug interactions & 2 & 4.1 \\
\hline Clinic inefficacy & 2 & 4.1 \\
\hline Discontinuation of therapy & 1 & 2.0 \\
\hline \multicolumn{3}{|l|}{ Pharmacist's interventions } \\
\hline Treatment adherence & 7 & 20.0 \\
\hline Adjustment the dose & 8 & 22.9 \\
\hline Change the frequency of the dose & 5 & 14.3 \\
\hline Modified therapeutic regimen & 5 & 14.3 \\
\hline Detection of adverse effects & 4 & 11.4 \\
\hline Reduce voluntary noncompliance & 6 & 17.1 \\
\hline
\end{tabular}

propranolol were prepared for the 63 patients. Education was given to relatives of all patients.

\section{Clinical Efficacy and Duration of Treatment}

The efficacy of propranolol was evaluated according to the established scale. Overall, $95.2 \%$ of patients obtained a satisfactory response to treatment. In general, therapy ended when the patient had a good or excellent response. The duration of treatment was $9.1 \pm 3.1$ months, depending on the location, type of $\mathrm{IH}$, and therapeutic response of the patient.

\section{Comparison Studies}

There was no control group during the study because of the limited number of patients. The results were compared with those of a multicenter study conducted worldwide by Léauté-Labrèze et al. [6], Chang et al. [12], and a systematic review by Marqueling et al. [7] where there was no active participation of a pharmacist reported during therapy of patients. The comparative results are shown in Table 2.

\section{DISCUSSION}

Until 2008, therapy for patients with IH was limited to corticosteroids as first-line treatment and procedures like surgery and laser treatment [2]. After the discovery by Léauté-Labrèze, numerous studies have been conducted to evaluate the efficacy and safety of propranolol, becoming the treatment of choice in patients with IH $[5,11,13,14]$. One disadvantage of this treatment is the lack of propranolol formulations adapted and available to the pediatric population. In Mexico and Latin American countries it is difficult and expensive to obtain the Hemangeol ${ }^{\circledR}$ solution marketed in Europe and the USA, so propranolol remains a limited treatment option in some countries. Currently, when propranolol is prescribed, commercial formulations for adults such as tablets or capsules are used, and the preparation and administration are done by parents at home. This increases the risk of inadequate dosage and might be a cause of non-adherence to prescribed treatment and treatment failure. 
Table 2 Comparison of studies without pharmacist's participation reported vs pharmacist intervention in patients with infantile hemangioma treated with propranolol

\begin{tabular}{llll}
\hline Outcome & $\begin{array}{l}\text { Pharmacist's } \\
\text { participation } \boldsymbol{n}=\mathbf{6 3}\end{array}$ & $\begin{array}{l}\text { Without participation } \\
\text { of the pharmacist } \\
\text { reported [6] } \boldsymbol{n}=\mathbf{4 5 6} \mathbf{6}^{\mathbf{a}}\end{array}$ & $\begin{array}{l}\text { Without participation } \\
\text { reported systematic } \\
\text { review [7] } \boldsymbol{n}=\mathbf{3 1}^{\mathbf{b}}\end{array}$ \\
\hline Adherence to treatment & $90.5 \%$ & $79 \%$ & $86 \%$ \\
Adverse reactions reported & $12.3 \%$ & $33 \%$ & $31.2 \%$ \\
Successful response to treatment & $95 \%$ & $77.2 \%$ & $82 \%$ \\
Regrowth of hemangioma & $4.7 \%$ & $14 \%$ & $17 \%$ \\
Discontinuation of therapy & $2 \%$ & $10.5 \%$ & $4 \%$ \\
Duration of treatment (months) & 9.1 & 6.2 & 6.4 \\
Dosage administered & $0.5-2.5 \mathrm{mg} / \mathrm{kg} / \mathrm{day}$ & $1-3 \mathrm{mg} / \mathrm{kg} / \mathrm{day}$ & $1-4 \mathrm{mg} / \mathrm{kg} / \mathrm{day}$ \\
Oral formulation & Extemporaneously & Hemangeol ${ }^{\circledR}$ oral solution & Oral solution, \\
& compounded syrup & & capsules, tablets \\
\hline
\end{tabular}

${ }^{a}$ International study evaluating Hemangeol ${ }^{\circledR}$ in patients with infantile hemangioma [6]

b Systematic review of propranolol use in hemangioma; analysis of 41 studies with average of 31 patients per study [7]

There are no published studies about the direct contribution of the pharmacist in the treatment of patients with IH. In the previous studies, intervention is limited to dispensing. This research emphasized the participation and intervention of the pharmacist, whose work included education of parents of the patients and the prevention of new and potential problems during treatment [15].

The extemporaneous preparation of propranolol syrup is one of the important functions of the pharmacist. With this formulation, treatment can be individualized, adapting the drug to the patient characteristics, which improves adherence. Additionally, this preparation results in a lower cost of US $\$ 8$ per month, compared with US $\$ 245$ for the patented formulation. This is a great benefit because most parents have limited economic resources. Another strategy to improve the therapy used in this study was the education of the parents and family members of patients, guiding them about the condition of the child and the use of propranolol. The effectiveness of these strategies was reflected by the good results obtained.

Pharmacotherapy follow-up in pediatric patients is an effective method for identifying and preventing problems with medication [16-18]. Of the 49 problems identified, nine were inadequate dosage at the start of the study and attributed to the lack of information of dosing parameters in the Mexican population. Problems detected and reported by the pharmacist to the attending physician were accepted $92 \%$ of the time. Of the 49 problems detected, 40 (81.2\%) were resolved. This implies that the participation of the pharmacist was effective. One of the problems detected was nonadherence due to the lack of commitment of parents to administer medication or poor acceptance by the child. In these patients, interventions facilitated continuous treatment without interruption, such as adding a flavoring to the syrup or providing a detailed dosing schedule. The use of the Dáder method for 
pharmacotherapeutic follow-up and the simple medication adherence questionnaire (SMAQ) facilitated pharmacist intervention and served to improve assessment $[14,19,20]$.

The efficacy of propranolol in patients in this study was shown by the decreased size and color of the $\mathrm{IH}$ in $95.2 \%$ of treated cases. This high efficacy rate is attributed to the continuous pharmacotherapy with propranolol without interruption (up to 13 months) as well as pharmacist monitoring and intervention. One of the main concerns after the end of therapy is the regrowth of the hemangioma. In this study only two cases of regrowth (4\%) occurred, compared to studies in European countries, where the treatment duration was on average 7 months and the percentage of regrowth was up to $17 \%$ of cases $[7,12]$.

In previous studies [9] most of the adverse reactions occurring in pediatric patients were due to poor adherence, inadequate administration, dosage and unsuitable formulations, among others, so the pharmacist participation is important for avoiding these problems. The reported side effects of $\beta$-blockers include hypotension, bradycardia, hypoglycemia, pulmonary symptoms, sleep disturbances, somnolence, cold extremities, and gastrointestinal (GI) complaints [7]. These adverse reactions are reversible, dose-dependent, and usually not serious. In a systematic review of 41 studies of 1189 children, 371 cases (31.2\%) had adverse reactions [7]. In our patients only $12.3 \%$ of patients had an adverse reaction, none of which were severe or reason for therapy discontinuation. For these patients an individualized plan was designed by the pharmacist to optimize their treatment. Pharmacist intervention was based on the prevention and early detection of adverse effects during therapy.
The principal limitation of this study was the lack of a control group without pharmacist intervention; however, results were compared with previous studies published in European and worldwide populations $[6,7,12]$ without reported clinical participation by a pharmacist. In our study, significant improvement in the therapeutic effect, better adherence, less regrowth of hemangioma, and less discontinuation of therapy were shown. The treating physicians in this study attributed the success of the patient treatments to the inclusion of a pharmacist on the health team.

Recently the death of a pediatric patient with IH treated with propranolol was reported in Canada [8]. For this reason it is important that physician consider following strict patient screening guidelines and to carefully assess the probabilities of harm and benefit before prescribing propranolol, and the pharmacist provide to the parents information and education about the correct use of propranolol during therapy, in order to obtain a better treatment for the patient $[8,11,13]$.

\section{CONCLUSIONS}

Pharmacist monitoring and intervention as well as individualized preparation of propranolol syrup resulted in prevention of and solution to problems related to the use of propranolol. It also contributed to greater adherence to treatment which was reflected in the highly successful response to therapy. The success of treatment depended on continuous patient medical supervision and education of parents by the pharmacist, which facilitated outpatient treatment. We suggest that the role of the pharmacist is very important to increase the efficacy and safety of the used of propranolol in patients with $\mathrm{IH}$. 


\section{ACKNOWLEDGMENTS}

The authors would like to express their thanks to Hospital Infantil de las Californias, QFB; Hermila Gonzalez and Dr. Victor Leon Villanueva for help in the realization of this study; and Philip O. Anderson for review of the manuscript. No funding or sponsorship was received for this study or publication of this article. All named authors meet the International Committee of Medical Journal Editors (ICMJE) criteria for authorship for this manuscript, take responsibility for the integrity of the work as a whole, and have given final approval for the version to be published.

Disclosures. Saul Castaneda, Esbeydy Garcia, Hermelinda De la Cruz, Samuel Melendez-Lopez, and Jose Sanchez-Palacio have nothing to disclose.

Compliance with Ethics Guidelines. All procedures followed were in accordance with the ethical standards of the responsible committee on human experimentation (institutional and national) and with the Helsinki Declaration of 1964, as revised in 2013. Informed consent was obtained from all patients for being included in the study. The study was approved by the ethics committee of the Children's Hospital of the Californias, and the parents of the patients signed an informed consent after agreeing to participate.

Open Access. This article is distributed under the terms of the Creative Commons AttributionNonCommercial 4.0 International License (http://creativecommons.org/licenses/by-nc/4. $0 /$ ), which permits any noncommercial use, distribution, and reproduction in any medium, provided you give appropriate credit to the original author(s) and the source, provide a link to the Creative Commons license, and indicate if changes were made.

\section{REFERENCES}

1. Chen T, Eichenfield L, Fallon S. Infantile hemangiomas: an update on pathogenesis and therapy. Pediatrics. 2013;131:99-106.

2. Sánchez-Carpintero I, et al. Propranolol en hemangiomas infantiles: eficacia clínica, riesgos y recomendaciones. Actas Dermosifiliogr. 2011;102:766-79.

3. Léauté-Labrèze C, Dumas de la Roque E, Hubi-che $\mathrm{T}$, et al. Propranolol for severe hemangiomas of infancy. N Engl J Med. 2008;358:2649-51.

4. Beth A, Peter C. Initiation and use of propranolol for infantile hemangioma: report of a consensus conference. Pediatrics. 2013;131:128-40.

5. Ma X, Zhao T, Xiao Y, et al. Preliminary experience on treatment of infantile hemangioma with low-dose propranolol in China. Eur J Pediatr. 2013;172(5):653-9.

6. Léauté-Labrèze $\mathrm{C}$, Hoeger $\mathrm{P}$, Mazereeuw-Hautie J, et al. A randomized, controlled trial of oral propranolol in infantile hemangioma. $\mathrm{N}$ Engl J Med. 2015;372:735-40.

7. Marqueling AL, Oza V, Frieden IJ, et al. Propranolol and infantile hemangiomas four years later: a systematic review. Pediatr Dermatol. 2013;30:182-91.

8. Infantile hemangioma treated with propranolol: learning opportunities from an infant death. ISMP Can Safe Bull. 1(1). February 18, 2016 [http://www. ismp-canada.org/download/safetyBulletins/2016/ ISMPCSB2016-01_propranolol.pdf. Accessed Apr 4, 2016].

9. Raspanti D, Fontana D, Soláuthurry N. Seguimiento farmacoterapéutico en pacientes pediátricos hospitalizados: adaptación de la metodología Dáder. Farm Hosp. 2003;27(2):78-83.

10. Ensom M, Kendrick J, Rudolph S, et al. Stability of propranolol in extemporaneously compounded suspensions. Can J Hosp Pharm. 2013;66(2):118-24.

11. Castaneda S, Garcia E, Sanchez-Palacio JL, et al. Therapeutic effect of propranolol in Mexican patients with infantile hemangioma. Drugs Real World Outcomes. 2016;3:25-31. 
12. Chang L, et al. Is propranolol safe and effective for outpatient use for infantile hemangioma? A prospective study of 679 cases from one center in China. Ann Plastic Surg. 2016;76(5):559-63.

13. Martinez Roca $C$, et al. Oral propranolol in the treatment of infantile hemangioma: a case series of 50 infants. Eur J Pediatr Dermatol. 2014;24:86-90.

14. Sorensen L, Stokes JA, Purdie DM, Woodward M, Elliot R, Roberts MS. Medication reviews in the community: results of a randomized, controlled effectiveness trial. $\mathrm{Br} \mathrm{J}$ Clin Pharmacol. 2005;59(3):376.

15. Isetts $\mathrm{BJ}$, Schondelmeyer $\mathrm{SW}$, Artz $\mathrm{MB}$, et al. Clinical and economic outcomes of medication therapy management services: the Minnesota experience. J Am Pharm Assoc. 2008;48:203-14.

16. Sabater D, Fernandez-Llimos F, Parras M, Faus MJ. Tipos de intervenciones farmacéuticas en seguimiento farmacoterapéutico. Seguimiento Farmacoterapéutico. 2005;3(2):90-7.
17. McDonough RP, Doucette WR. Drug therapy management: an empirical report of drug therapy problems, pharmacist's interventions, and results of pharmacists' actions. J Am Pharm Assoc (Washington DC). 2003;43:511-8.

18. Charrois T, Durec T, Tsuyuki RT. Systematic reviews of pharmacy practice research: methodologic issues in searching, evaluating, interpreting, and disseminating results. Ann Pharmacother. 2009;43:118-22.

19. Sanchez A, Gallardo S, Pons N, et al. Intervención farmacéutica al alta hospitalaria para reforzar la comprensión y cumplimiento del tratamiento farmacológico. Farm Hosp. 2012;36(3):118-23.

20. Chemello C, Aguilera M, Calleja-Hernández MA, et al. Efecto del seguimiento farmacoterapéutico en pacientes con hiperparatiroidismo secundario tratados con cinacalcet. Farm Hosp. 2012;36(5):321-7. 